became an agricultural animal. At best, it seems, farmers are faced with a choice of evils. The labour force in agriculture declines by five per cent a year, and productivity per man must increase. If ploughs are to be retained, then tractors must become larger, fields must become larger and hedges must come down, which itself is a violation of the countryside as it is.

Criticism from conservationists has been quite deeply felt within the pesticide industry, which is on its own initiative lobbying the British Government to introduce a compulsory scheme for the registration of pesticides. The present scheme is voluntary. But manufacturers have shown little enthusiasm for the idea that defoliants should be subject to the terms of the Geneva Convention on biological warfare. Several defoliants of British invention are apparently being used in Vietnam. The current safety regulations cope fully with the toxicity of pesticides but take no account of persistence. Most chemicals are soon destroyed by bacteria in the soil, but "Picloram", a herbicide produced by Dow Chemical, is exceptional in its resistance to bacterial attack. There is therefore a risk that it might accumulate in waterways and spread to untreated ground. "Picloram" is being withdrawn from use as stocks run out, and moves are afoot to add a persistence clause to the pesticide regulations.

\section{SI UNITS}

\section{Recalcitrant Physicists}

BRITISH physicists, like engineers and chemists, seem reluctant to adopt the full-blooded version of the international system (SI) of units. Attempts were made to define the areas where there is fundamental disagreement at a meeting held last week by the Royal Society to discuss the use of SI units in physies.

Professor M. J. Lighthill, who ran the meeting, pleaded that physicists should be prepared to make some concessions for the sake of establishing a coherent common language for communication between scientists from different countries and from different disciplines. He realized that in some fields, like nuclear physics and astrophysies, the orders of magnitude involved are such that SI units are inappropriate, and that non-dimensional systems of units are so useful that they should not be abandoned, but he thought that in most other fields SI units could bo successfully incorporated.

Professor F. C. Frank from Bristol agreed that the present system of units should be reformed and stressed that half measures, like the use of the kg-force instead of the lb-force, should be avoided. He thought that objections to particular SI units on the grounds of current familiarity or because their orders of magnitudes are less convenient than those of conventional units did not carry much weight. The SI unit cannot differ by more than a factor of 10 from the conventional unit, because a thousand times or a thousandth of each unit is another allowed unit. But valid objections could be made to the use of SI units in electromagnetism, he thought. Physically the quantities magnetic field and magnetic induction, and electric field and displacement, are similar, but they have different SI units. Another objection to SI is that in high precision work physical quantities like volume can be compared to precisions of parts in $10^{7}$, but can be determined in terms of the basic SI unit to precisions of only parts in $10^{4}$. Most physicists work in a particular field and do not need to communicate outside this field, and Professor R. G. Chambers, also from Bristol, agreed that different dialects should be allowed. He defended the spectroscopists' use of the Ångstrom and $\mathrm{cm}^{-1}$ which are not recognized metric units. The Inter-Union Commission for Spectroscopy which represents the views of most spectroscopists, issued a statement in July in support of the Angstrom and $\mathrm{cm}^{-1}$. Some members of the commission recommended the indefinite preservation of these units. Crystallographers also like the Ångstrom because it is a convenient unit for interatomic distances and chemical bond lengths.

Sir Harrie Massey, chairman of the Council for Scientifie Policy, hoped that scientists writing books or contributing to journals would not be forced to use SI units exclusively. If an authoritarian editorial policy were adopted, he warned, authors would probably send their manuscripts to the United States. A spokesman for the Royal Society said that, in the pamphlet it has prepared on the use of signs, symbols and abbreviations in scientific journals, it recommends that editors should insist on the use of the recommended symbols for physical quantities, and the definition once in a paper of any non-SI unit used, and that they should progressively discourage the use of non-SI units.

The question of the units to be used for pressure remains a vexed one and Dr Fielden from the British Standards Institution explained that the BSI would like to see the $\mathrm{N} / \mathrm{mm}^{2}$ or $\mathrm{MN} / \mathrm{m}^{2}$ as the unit of pressure. Because some industries were already using the hbar $\left(10 \mathrm{~N} / \mathrm{mm}^{2}\right.$ ), however, the institute would probably issue standards showing both units for some time, hoping that the basic unit would gradually be accepted.

\section{EPIDEMIOLOGY}

\section{Unpredictable Bug}

Hong Kong influenza, now making its debut in Europe and the United States of America, has spread rapidly since it originated in Hong Kong and neighbouring areas of China in mid-July. Nobody can predict if and when a large-scale epidemic is likely to break out in Britain, although previous experience of influenza epidemics points to late December and early January as "target" months, and similar dates have been quoted for an expected increase in the incidence of influenza in the United States. Reactions range from cheerful optimism to great consternation-particularly on the part of Mr Eric Moonman, chairman of the Labour Party's Science and Technology Committee, who is questioning the Government's plans to deal with an epidemic.

Because the new strain of virus differs quite considerably from the older A2 strain which it has displaced, existing supplies of vaccine against A2 Singapore provide very little protection against Hong Kong influenza. Consequently, three British drug companies are manufacturing new vaccine for immunization-in the first instance of the aged and chronically sick, in accordance with instructions from the Ministry of Health (Department of Health and Social Security). Beecham's Research Laboratories went into production at the end of August and started to distribute vaccine about 2 weeks ago. Crookes Laboratories Ltd also 